\title{
Prevalence and risk factors for chronic kidney disease of unknown cause in Malawi: a cross-sectional analysis in a rural and urban population
}

Sophie A. Hamilton ${ }^{1,2,3^{*}}$ (D) Wisdom P. Nakanga ${ }^{4}$, Josephine E. Prynn ${ }^{4,5}$, Amelia C. Crampin ${ }^{4,6}$, Daniela Fecht ${ }^{1,2}$, Paolo Vineis ${ }^{1,2}$, Ben Caplin ${ }^{7}$, Neil Pearce ${ }^{8,9}$ and Moffat J. Nyirenda ${ }^{4,6}$

\begin{abstract}
Background: An epidemic of chronic kidney disease of unknown cause (CKDu) is occurring in rural communities in tropical regions of low-and middle-income countries in South America and India. Little information is available from Southern African countries which have similar climatic and occupational characteristics to CKDu-endemic countries. We investigated whether CKDu is prevalent in Malawi and identified its potential risk factors in this setting.

Methods: We conducted a cross-sectional study from January-August 2018 collecting bio samples and anthropometric data in two Malawian populations. The sample comprised adults $>18$ years $(n=821)$ without diabetes, hypertension, and proteinuria. Estimates of glomerular filtration rate (eGFR) were calculated using the CKD-EPI equation. Linear and logistic regression models were applied with potential risk factors, to estimate risk of reduced eGFR.

Results: The mean eGFR was $117.1 \pm 16.0 \mathrm{ml} / \mathrm{min}$ per $1.73 \mathrm{~m}^{2}$ and the mean participant age was $33.5 \pm 12.7$ years. The prevalence of eGFR< 60 was $0.2 \%$ ( $95 \%$ confidence interval $(95 \% \mathrm{Cl})$ 0.1, 0.9); the prevalence of eGFR $<90$ was $5 \%(95 \% \mathrm{Cl}=3.2,6.3)$. We observed a higher prevalence in the rural population $(5 \%(3.6,7.8))$, versus urban $(3 \%(1.4$, $6.7))$. Age and BMI were associated with reduced eGFR< 90 [Odds ratio $(\mathrm{OR})(95 \% \mathrm{Cl})=3.59(2.58,5.21)$ per ten-year increment]; [OR $(95 \% \mathrm{Cl})=2.01(1.27,3.43)$ per $5 \mathrm{~kg} / \mathrm{m}^{2}$ increment] respectively. No increased risk of eGFR $<90$ was observed for rural participants [OR $(95 \% \mathrm{Cl})=1.75(0.50,6.30)]$.

(Continued on next page)
\end{abstract}

\footnotetext{
* Correspondence: s.hamilton16@imperial.ac.uk

'Department of Epidemiology and Biostatistics, Imperial College London, London, UK

${ }^{2}$ MRC Centre for Environment and Health, Imperial College London, London, UK

Full list of author information is available at the end of the article
}

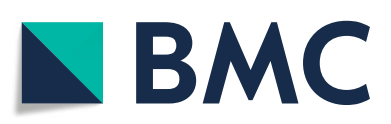

() The Author(s). 2020 Open Access This article is licensed under a Creative Commons Attribution 4.0 International License, which permits use, sharing, adaptation, distribution and reproduction in any medium or format, as long as you give appropriate credit to the original author(s) and the source, provide a link to the Creative Commons licence, and indicate if changes were made. The images or other third party material in this article are included in the article's Creative Commons licence, unless indicated otherwise in a credit line to the material. If material is not included in the article's Creative Commons licence and your intended use is not permitted by statutory regulation or exceeds the permitted use, you will need to obtain permission directly from the copyright holder. To view a copy of this licence, visit http://creativecommons.org/licenses/by/4.0/. The Creative Commons Public Domain Dedication waiver (http://creativecommons.org/publicdomain/zero/1.0/) applies to the data made available in this article, unless otherwise stated in a credit line to the data. 


\begin{abstract}
(Continued from previous page)
Conclusions: Reduced kidney function consistent with the definition of CKDu is not common in the areas of Malawi sampled, compared to that observed in other tropical or sub-tropical countries in Central America and South Asia. Reduced eGFR< 90 was related to age, BMI, and was more common in rural areas. These findings are important as they contradict some current hypothesis that CKDu is endemic across tropical and sub-tropical countries. This study has enabled standardized comparisons of impaired kidney function between and within tropical/subtropical regions of the world and will help form the basis for further etiological research, surveillance strategies, and the implementation and evaluation of interventions.
\end{abstract}

Keywords: Epidemiology, Chronic kidney disease, Estimated glomerular filtration rate, Prevalence, Risk factor, SubSaharan Africa

\section{Background}

An epidemic of chronic kidney disease of unknown cause $(\mathrm{CKDu})$ is occurring in rural communities in an increasing number of low-and middle-income countries (LMICs) [1, 2]. The highest prevalence of CKDu has been reported in Nicaragua, Central America [3, 4] where $10-20 \%$ of the adult population are affected $[5,6]$. $\mathrm{CKDu}$ has also been reported in other rural communities across Southern India and Sri Lanka where the prevalence is 1.6 and $1.5 \%$ respectively $[7,8]$.

$\mathrm{CKDu}$ is defined by an estimated glomerular filtration rate (eGFR) of $<60 \mathrm{ml} / \mathrm{min}$ per $1.73 \mathrm{~m}^{2}$ in the absence of traditional risk factors such as diabetes, hypertension, heavy proteinuria, and structural renal disease, based on two measures of serum creatinine 3 months apart $[2,9$, 10]. Histopathology reports from previous CKDu studies show that tubular atrophy and interstitial fibrosis in the presence of varying degrees of glomerulosclerosis are the predominant features of CKDu $[2,11]$. However, to date, there are few examples of consistent approaches and case definitions across countries which have conducted $\mathrm{CKDu}$ research, which makes international comparisons challenging $[2,12]$. As a result, it is unclear whether there is an underlying aetiology or causal pathway of the condition, and indeed whether it occurs in other regions of the world. However, there is consensus in the research landscape on the possible range of risk factors predominantly heat stress [13-15], agricultural labour [16] and heavy metal exposure [17], which are factors largely associated with rural habitation.

CKDu has been reported in Central America and South Asia, however little information is available from Southern African countries, which have similar climatic and occupational characteristics to reported $\mathrm{CKDu}$ endemic regions. Malawi was selected as our study location as previous research in urban and rural Malawi demonstrated a significant association with impaired kidney function and agricultural labour - a central hypothesis in the CKDu literature [18] which warranted further research measuring eGFR applying a different diagnostic definition.
The aim of this study was to estimate the distribution of eGFR in an urban and rural area of Malawi to identify the presence of CKDu. We aimed to: (i) assess eGFR distribution and prevalence of eGFR below $60 \mathrm{ml} / \mathrm{min}$ per $1.73 \mathrm{~m}^{2}(\mathrm{eGFR}<60)$ and eGFR below $90 \mathrm{ml} / \mathrm{min}$ per $1.73 \mathrm{~m}^{2}$ (eGFR $\left.<90\right)$ in a population restricted to those without known risk factors for CKD, i.e. diabetes, hypertension or heavy proteinuria; (ii) compare these outcomes between urban and rural populations; and (iii) identify anthropometric and lifestyle-related risk factors associated with these outcomes.

\section{Methods}

The Disadvantaged Populations eGFR Epidemiology (DEGREE) Study [1] is a collaboration which has produced a standardised protocol for estimating the population distribution of the estimated glomerular filtration rate (eGFR) distribution in LMICs. This involves quantification of renal function in a representative adult population-based sample with standardisation of serum creatinine measurements, storage of samples for future measurements of cystatin $\mathrm{C}$ and ascertainment of body composition estimates to obtain valid comparisons within and between populations. The DEGREE methodologies are described in detail elsewhere [1]. Here we report the results from a DEGREE study conducted in Malawi, south-east Africa.

\section{Study population}

The DEGREE survey was conducted in northern rural Karonga District, and Malawi's capital city Lilongwe (Fig. 1). The rural survey in Karonga District was nested in the well-established Health and Demographic Surveillance Site (HDSS) $\left(135 \mathrm{~km}^{2}\right.$ area, population 40,000) [19] in a predominantly subsistence economy. The sample frame is located in Bonje, a village area including a large commercial rice irrigation scheme. The urban survey in Lilongwe was situated in a sub-area of Area $25\left(10 \mathrm{~km}^{2}\right.$ area, population 66,000 [20]) a high-density, economically mixed residential area. The sub-area selected is one 


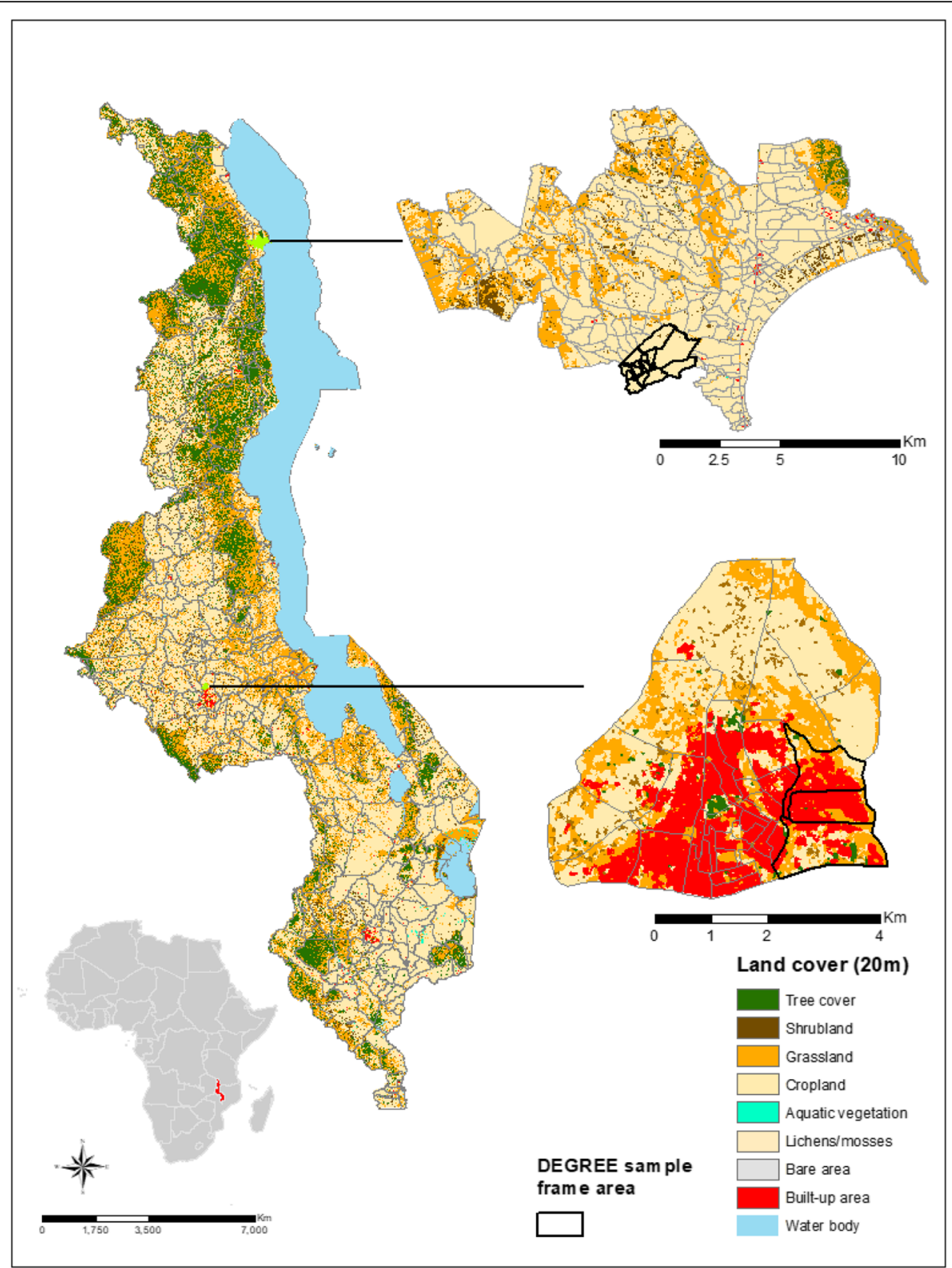

Fig. 1 Malawi study sites; a) Bonje sample frame; b) Area 25 sample frame

of the more deprived areas where casual and seasonal labourers reside.

In Karonga, 1200 participants aged 18 years and older were randomly sampled at the individual level from the existing HDSS sample frame for the selected area. In Lilongwe, it was anticipated that many residents would have moved since the 2013 enumeration for the NCD survey. We re-enumerated the area and used a new list of residents as a sampling frame. This was done by dividing the geographical area within Area 25 into zones of approximately 100 households each and enumerating each at a time. After each zone was enumerated, 1 in 3 adults were randomly sampled.

\section{Data collection and laboratory analyses}

Data collection was conducted between January and August 2018. Participants were interviewed using a standardized questionnaire collecting data on basic co-variates (age, sex, years of schooling), lifestyle factors (alcohol intake, smoking, meat consumption as number of days per week), medical history (previous diagnoses of hypertension, diabetes and analgesic use), and occupational status (including information on workload and financial income).

Height and weight were measured twice per visit for each participant using calibrated Stadiometer seca-213, Scales seca-761 apparatus respectively (seca $\mathrm{GmbH} \&$ 
Co. KG, Germany), and the mean values calculated. Body composition was measured using a Bodystat 1500 bioimpedance analysis (BIA) instrument (Bodystat Ltd., United Kingdom). Fat-free mass (FFM) was calculated using the mean value of two bioimpedance output measures (fat free mass/lean mass, $\mathrm{kg}$ ). Body mass index $\left(\mathrm{BMI}, \mathrm{kg} / \mathrm{m}^{2}\right)$ was calculated and categorized as underweight: $\leq 18.5$, normal weight: $>18.5-\leq 25$, overweight: > $25-\leq 30$, and obese: $>30$.

Blood pressure was measured with a portable electronic device OMRON HEM-7211-E, Model M6 (OMRON Healthcare Co., Ltd., Japan) on the right upper arm, three times in a seated position after $30 \mathrm{~min}$ of inactivity and 5 min rest between measurements. Participants were classified as having hypertension if systolic blood pressure was $\geq 140 \mathrm{mmHg}$, or diastolic blood pressure was $\geq 90 \mathrm{mmHg}$, or if the participant was on antihypertensive medication.

First-urine (early morning) and fasting venous blood samples were taken by clinical field staff. Urine was tested for albumin using the photometric colour test method, and blood samples were tested using the hexokinase and Kinetic Jaffé compensated methods to measure glucose and serum creatinine. Serum creatinine samples were measured in the Malawi Epidemiology and Intervention Research Unit laboratories located in Lilongwe and Karonga using a method calibrated to isotope dilution mass spectrometry (IDMS) standards. Participants were categorized as heavily proteinuric if the albumin: creatinine ratio (ACR) was $\geq 30 \mathrm{mg} / \mathrm{mmol}$, and diabetic if fasting plasma glucose was $\geq 7 \mathrm{mmol} / \mathrm{L}$, or if the participant self-reported diabetes and on hypoglycaemic medication.

The CKD Epidemiology Collaboration (CKD-EPI) equation was used to calculate eGFR [1]. No correction for ethnicity was applied as many studies from Sub Saharan Africa which include coefficients for African American ethnicity consistently overestimate GFR [21-25]. Clinical diagnosis of CKDu is based on two measures 3 months apart [26], which is not practical in most epidemiological studies, thus our main outcome measure was eGFR $<60$ without known risk factors of kidney disease [7].

\section{Statistical analysis}

The DEGREE protocol specifies a diagnostic cut off for impaired kidney function of eGFR $<60 \mathrm{ml} / \mathrm{min}$ per $1.73 \mathrm{~m}^{2}$ for reduced function in the absence of diabetes, hypertension, and heavy proteinuria [1]. There were few cases of impaired kidney function using this definition (see Results below). We therefore decided to investigate risk factors for an eGFR below normal $\left(<90 \mathrm{ml} / \mathrm{min}\right.$ per $\left.1.73 \mathrm{~m}^{2}\right)$, in the absence of known CKD risk factors.
We used linear regression models to estimate associations between potential risk factors (Table 1) and continuous eGFR, and logistic regression to estimate associations between risk factors and reduced eGFR.

We repeated analyses separately for urban and rural areas. We re-grouped co-variates into broader categories before conducting analyses (See Additional file 1, Table S1 for original categories) due to the small proportion of those with eGFR $<90$.

Variables associated with lower eGFR in univariate analyses (adjusted for age, sex, and study site) were included in the multiple regression analysis. In the final multiple regression model, variables showing independent association with eGFR, and those of a-priori interest identified via literature searches (study site, sex, and education) were included.

We checked for multicollinearity of each variable in the multiple regression analysis in comparison to the univariate analysis [27]. All analyses were conducted using R studio version 3.5.1.

\section{Results \\ Study population characteristics}

The overall response rate was $56 \%(n=1076$ participants out of 1908 eligible; 654 females, 422 males). Participants were "missed" if field staff had visited the residence on three occasions to invite them to participate in the study but did not find them at home $(n=559 ; 189$ females, 367 males, 3 missing all data variables). A total of 201 individuals were found but were unwilling to participate in the informed consent procedures (initial refusers) (115 females, 83 males, 3 missing all data variables). Using a priori exclusion criteria, we then removed participants with missing basic variables including date of birth, and those with the known CKD risk factors diabetes, hypertension, or heavy proteinuria (Fig. 2). After exclusions, 821 participants were eligible for analysis (Fig. 2). Table 1 summarizes sociodemographic and anthropometric characteristics of the sample (see Additional file 1, Table S1 for the nonrestricted sample, $n=1076$ ).

The mean (standard deviation $( \pm \mathrm{SD})$ ) participant age was $33.5 \pm 12.7$ years. Mean BMI was $23.4 \pm 3.9 \mathrm{~kg} / \mathrm{m}^{2}$, and mean FFM was $51.7 \pm 82.3 \mathrm{~kg}$. Mean systolic and diastolic blood pressure were $116.5 \pm 10.3 \mathrm{mmHg}$, and $70.7 \pm 8.3 \mathrm{mmHg}$, respectively. Mean fasting plasma glucose was $4.7 \pm 0.7 \mathrm{mmol} / \mathrm{l}$ and the median (interquartile range IQR) albumin: creatinine ratio (ACR) was $0.5(0.8)$ $\mathrm{mg} / \mathrm{mmol}$ after exclusion of those with ACR $>=30 \mathrm{mg} /$ mmol, $n=13$ ).

There was an $82 \%$ employment rate in the population (females, $n=390$ [77\%], males, $n=286$ [90\%]), approximately $57 \%$ of which were classified as agricultural workers (females, $n=235$ [61\%], males, $n=148$ [39\%]). 
Table 1 Sociodemographic and anthropometric characteristics of study participants without diabetes, hypertension, and heavy proteinuria) $n=821$

\begin{tabular}{|c|c|c|c|c|c|}
\hline \multirow[t]{3}{*}{ Variable } & \multirow{2}{*}{\multicolumn{2}{|c|}{$\begin{array}{l}\text { eGFR } \\
n=821\end{array}$}} & \multicolumn{3}{|c|}{ eGFR categories, $\mathrm{n}(\%)^{\mathrm{b}}$} \\
\hline & & & \multirow{2}{*}{$\begin{array}{l}n=2 \\
<60\end{array}$} & \multirow{2}{*}{$\begin{array}{l}n=36 \\
>=60,<90\end{array}$} & \multirow{2}{*}{$\begin{array}{l}n=783 \\
>=90\end{array}$} \\
\hline & $n(\%)^{a}$ & Mean (SD) & & & \\
\hline \multicolumn{6}{|l|}{ Age (years) } \\
\hline$<20$ & $60(7)$ & $132.6(13.2)$ & 0 & $1(2)$ & $59(98)$ \\
\hline $20-29$ & $312(38)$ & $125.1(12.6)$ & 0 & $2(1)$ & $310(99)$ \\
\hline $30-39$ & $232(28)$ & $115.7(12.5)$ & $1(0.4)$ & $4(2)$ & $227(98)$ \\
\hline $40-49$ & $130(16)$ & $107.8(11.1)$ & $1(1)$ & $2(2)$ & $127(98)$ \\
\hline $50-59$ & $46(6)$ & $100.9(8.6)$ & 0 & $6(12)$ & $40(87)$ \\
\hline $60+$ & $41(5)$ & $88.9(9.9)$ & 0 & $21(51)$ & $20(49)$ \\
\hline \multicolumn{6}{|l|}{ Sex } \\
\hline Female & $504(61)$ & $117.3(15.6)$ & $2(0.4)$ & $20(4)$ & $482(96)$ \\
\hline Male & $317(39)$ & $116.81(16.7)$ & 0 & $16(5)$ & $301(95)$ \\
\hline \multicolumn{6}{|l|}{ Area } \\
\hline Urban (Area 25) & $243(29)$ & $117.6(14.9)$ & $1(0.4)$ & $6(3)$ & $236(97)$ \\
\hline Rural (Bonje) & $578(71)$ & $116.9(16.5)$ & $1(0.2)$ & $30(5)$ & $547(95)$ \\
\hline \multicolumn{6}{|l|}{ Education (years) } \\
\hline$\leq 5$ & $59(7)$ & $109.1(17.9)$ & 0 & $9(15)$ & $50(85)$ \\
\hline$>5 \leq 10$ & $301(36)$ & $116.6(16.4)$ & $1(0.2)$ & $15(3)$ & $285(62)$ \\
\hline$>10$ & $461(56)$ & $118.5(15.2)$ & $1(0.3)$ & $12(4)$ & $448(14)$ \\
\hline \multicolumn{6}{|l|}{ Occupation } \\
\hline Agricultural worker & $383(47)$ & $113.9(15.2)$ & $1(0.3)$ & $20(5)$ & $362(95)$ \\
\hline Non-agricultural worker & $438(53)$ & $119.90(16.2)$ & $1(0.2)$ & $16(4)$ & $421(96)$ \\
\hline \multicolumn{6}{|l|}{ Household monthly income $(\mathrm{MK})^{\mathrm{c}}$} \\
\hline Unknown & $17(1)$ & $118.6(21.1)$ & $1(6)$ & 0 & $16(94)$ \\
\hline MK $0 \leq 20,000$ & $406(50)$ & $117.8(16.6)$ & 0 & $20(5)$ & $386(95)$ \\
\hline MK $>20,000$ & $398(49)$ & $116.3(15.1)$ & $1(0.3)$ & $16(4)$ & $381(96)$ \\
\hline \multicolumn{6}{|l|}{ Healthy lifestyle choices } \\
\hline Non-smoker/ never drink alcohol & $630(77)$ & $117.0(15.8)$ & $2(0.3)$ & $28(4)$ & $600(95)$ \\
\hline Smoker/ alcohol drinker & $191(23)$ & $117.3(16.4)$ & 0 & $8(4)$ & $183(96)$ \\
\hline \multicolumn{6}{|l|}{ Regular meat-eater } \\
\hline Yes & $621(76)$ & $117.5(15.6)$ & $2(0.3)$ & $25(4)$ & $594(96)$ \\
\hline No & $200(24)$ & $115.6(16.1)$ & 0 & $11(6)$ & $189(95)$ \\
\hline \multicolumn{6}{|l|}{ Body mass index $\left(\mathrm{kg} / \mathrm{m}^{2}\right)$} \\
\hline Underweight $(\leq 18.5)$ & $45(6)$ & $121.6(18.0)$ & 0 & $3(7)$ & $42(93)$ \\
\hline Normal (> $18.5-\leq 25)$ & $545(66)$ & $118.4(15.4)$ & 0 & $17(3)$ & $528(97)$ \\
\hline Overweight (> $25-\leq 30)$ & $177(22)$ & $113.3(15.1)$ & $2(1)$ & $7(4)$ & $168(95)$ \\
\hline Obese (> 30) & $54(7)$ & $112.1(17.8)$ & 0 & $9(17)$ & $45(83)$ \\
\hline \multicolumn{6}{|l|}{ Fat-free mass (kg) } \\
\hline 1st tertile $(\leq 37)$ & $124(15)$ & $115.1(16.3)$ & 0 & $8(7)$ & $116(94)$ \\
\hline 2nd tertile $(>37-<45)$ & $354(43)$ & $116.9(16.9)$ & $2(1)$ & $18(5)$ & $334(94)$ \\
\hline 3rd tertile $(\geq 45)$ & $343(42)$ & $117.9(14.9)$ & 0 & $10(3)$ & $333(97)$ \\
\hline \multicolumn{6}{|l|}{ HIV status } \\
\hline Positive & $3(0.4)$ & $114.3(15.1)$ & 0 & 0 & $3(100)$ \\
\hline
\end{tabular}


Table 1 Sociodemographic and anthropometric characteristics of study participants without diabetes, hypertension, and heavy proteinuria) $n=821$ (Continued)

\begin{tabular}{|c|c|c|c|c|c|}
\hline \multirow[t]{3}{*}{ Variable } & \multirow{2}{*}{\multicolumn{2}{|c|}{$\frac{\text { eGFR }}{n=821}$}} & \multicolumn{3}{|c|}{ eGFR categories, $\mathrm{n}(\%)^{\mathrm{b}}$} \\
\hline & & & \multirow{2}{*}{$\begin{array}{l}n=2 \\
<60\end{array}$} & \multirow{2}{*}{$\begin{array}{l}n=36 \\
>=60,<90\end{array}$} & \multirow{2}{*}{$\begin{aligned} n & =783 \\
> & =90\end{aligned}$} \\
\hline & $\overline{n(\%)^{a}}$ & Mean (SD) & & & \\
\hline Negative & $595(73)$ & $116.8(15.1)$ & $1(0.2)$ & $24(4)$ & $570(96)$ \\
\hline Unknown & $223(27)$ & $118.0(18.1)$ & $1(0.4)$ & $12(5)$ & $210(94)$ \\
\hline
\end{tabular}

apercentage in columns

${ }^{b}$ percentage in rows

${ }^{\mathrm{C}}$ Exchange rate (MK to USD) 0.001 at time of questionnaire

$56 \%$ of the population completed $\geq 10$ years of formal education.

\section{Mean eGFR and prevalence of reduced eGFR}

The mean eGFR was $117.1 \pm 16.0 \mathrm{ml} / \mathrm{min}$ per $1.73 \mathrm{~m}^{2}$. We observed a lower eGFR with increasing age, increasing BMI, for agricultural workers, for those with fewer years of schooling ( $\leq 5$ years), for higher income, nonregular meat-eaters (those eating meat 0 days per week) with decreasing fat-free mass, and HIV seropositivity. We observed small site and sex-specific differences in mean eGFR; the mean was $117.6( \pm 14.9)$ for urban participants, and $116.9( \pm 16.5)$ for rural participants and 116.8 $( \pm 16.7), 117.3( \pm 15.6)$ for males and females, respectively. Figure 3 shows the eGFR distribution in the sample population.

The prevalence of eGFR $<60$ in the study population was $0.2 \%(95 \% \mathrm{CI} 0.1,0.9)$, and the prevalence of eGFR<

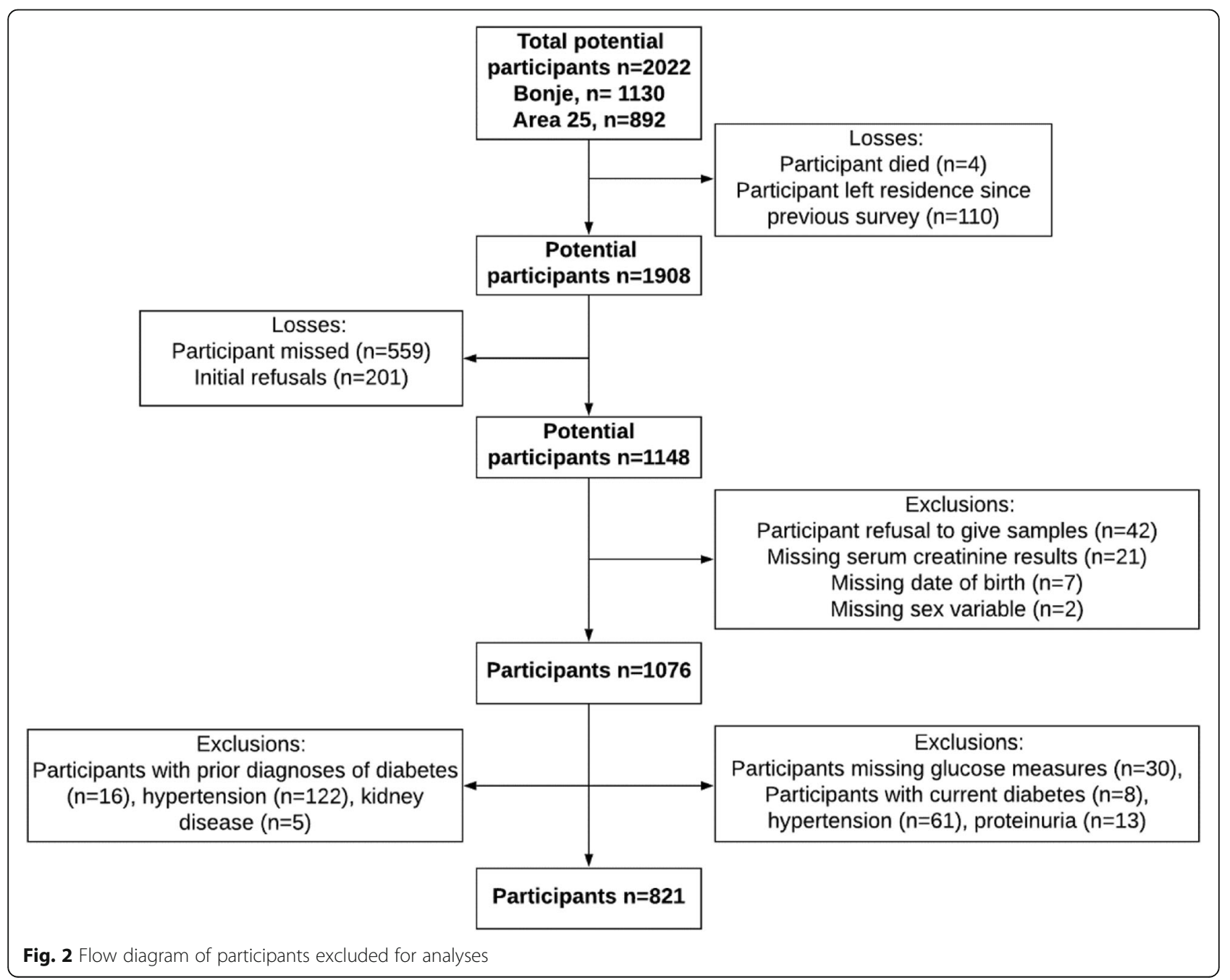




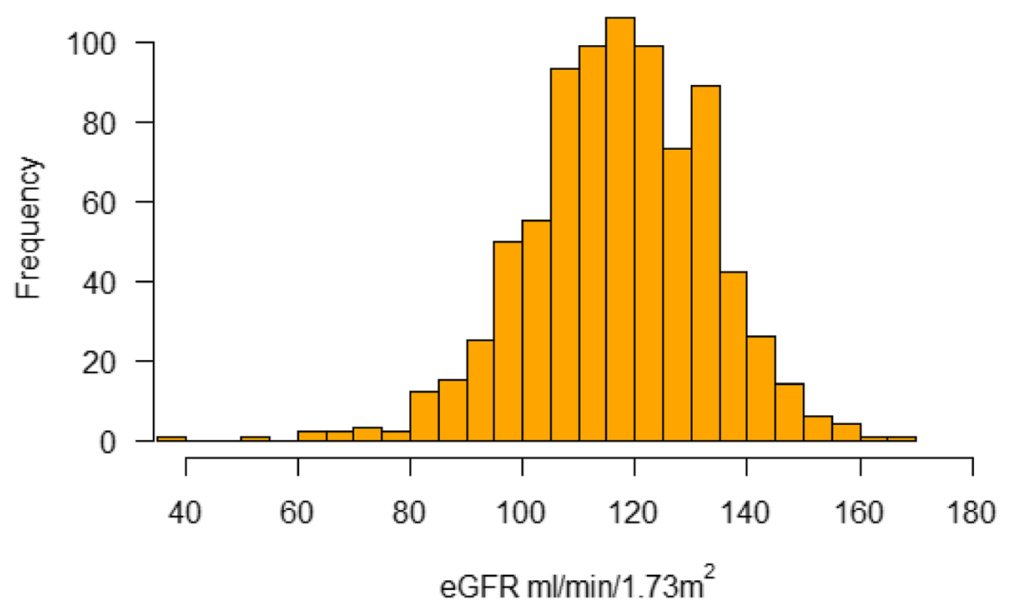

Fig. 3 Histogram of eGFR distribution in the sample population

90 was $5 \%(95 \%$ confidence interval $(95 \% \mathrm{CI})=3.2,6.3)$. We observed small differences in reduced eGFR $(<90)$ prevalence by site, with $3 \%(1.4,6.7)$ in (urban) Area 25 , versus $5 \%(3.6,7.8)$ in (rural) Bonje (Table 1$)$.

\section{Risk factors for reduced eGFR and eGFR $<90$}

We first conducted linear and logistic regression models which included all potential risk factors and confounders; however, due to the small number of participants with an eGFR $<90(n=38)$, we also repeated the models minimally adjusted for key risk factors and confounders to test for inflation of relative risk due to sparse data. There was little difference between the findings from the fully adjusted and minimally adjusted models, therefore we report results from the fully adjusted models only. Table 2 shows linear and logistic regression models mutually adjusted for age, sex and location (models 1 and 3), and fully adjusted for all risk factor variables (age, sex, location, BMI, FFM, education, occupational status, lifestyle choices, income and non-regular meat-eaters (models 2 and 4). Age was analysed as a continuous variable (in 10-year increments) to estimate overall age-related associations with continuous eGFR in the sample population. HIV status was not included in further analyses due to the small proportion of seropositive participants, and the large proportion of participant with unknown HIV status. Results showed no marked differences between eGFR and levels of adjustment for risk factors $(<10 \%$ change in regression coefficients), thus we report results from the fully adjusted models (2 and 4) only.

In the fully adjusted linear regression model (Table 2, model 2), age was a key risk factor for lower eGFR [regression coefficient $(95 \% \mathrm{CI})=-8.86(-9.60,-8.15)]$ per ten-year age increase. Rural residence was independently associated with higher eGFR $[3.82(1.51,6.32)]$ despite this site having the higher prevalence of eGFR $<90(6 \%)$. Education level $<5$ years was also associated with higher eGFR $[4.29(0.77,7.69)]$. No associations were observed between lower eGFR and sex, or occupational status.

Similarly, in the fully adjusted logistic regression model (model 4), the odds of reduced eGFR $<90$ increased with age $[\mathrm{OR}=3.59(2.58,5.21)]$ per ten-year increase, and with increasing $\mathrm{BMI}[\mathrm{OR}=2.01(1.27,3.43)]$ per $5 \mathrm{~kg} / \mathrm{m}^{2}$ weight increase. No increased risk of eGFR $<90$ with sex, study site, or occupational status was observed.

\section{Urban-rural comparison of eGFR}

As CKDu had been found to be a predominantly rural disease in areas where it is endemic, we conducted regression analyses to assess site-specific risk factors. We report linear and logistic regression results from fully adjusted models for Bonje (Table 3, models 1, 2). Due to the small proportion of participants in the eGFR $<90$ category in the urban population, we could not conduct logistic regression analyses for Area 25 and thus report fully adjusted linear regression results (model 3). For minimally adjusted models, refer to Additional files 2 and 3, Tables S2 and S3.

Within each site, increasing age was associated with lower eGFR, and risk of reduced eGFR (models 1-3). In Bonje, education $<5$ years was associated with higher eGFR $[4.19(0.39,7.99)]$. After further stratification by age however, this association was lost, suggesting age was confounding this relationship due to a higher proportion of younger participants in this category having an eGFR $>90$ in comparison to the other education-level categories. In logistic regression, increasing BMI was associated with risk of eGFR $<90$ (models $1-2$ ). No associations were observed between reduced eGFR and sex or occupational status within either study site. 
Table 2 Associations between sociodemographic and anthropometric characteristics and eGFR/eGFR<90 in participants without diabetes, hypertension, proteinuria, $n=821$

\begin{tabular}{|c|c|c|c|c|}
\hline Variable & $\begin{array}{l}\text { Model } 1 \text { Minimal adjustment } \\
\text { eGFR } \\
\text { Coefficient }(95 \% \mathrm{Cl})^{\text {a. }} \text {; }\end{array}$ & $\begin{array}{l}\text { Model } 2 \text { Fully adjusted } \\
\text { eGFR } \\
\text { Coefficient }(95 \% \mathrm{Cl})^{\mathrm{b}} ;\end{array}$ & $\begin{array}{l}\text { Model } 3 \text { Minimal adjustment } \\
\text { eGFR }<90 \\
\text { OR }(95 \% \mathrm{Cl})^{\text {a. }}\end{array}$ & $\begin{array}{l}\text { Model 4Fully adjusted } \\
\text { eGFR < } 90 \\
\text { OR }(95 \% \mathrm{Cl})^{\text {b; }}\end{array}$ \\
\hline Age $^{c}$ (per 10-year increase) & $-8.73(-9.37,-8.09)$ & $-8.86(-9.60,-8.15)$ & $3.21(2.49,4.29)$ & $3.59(2.58,5.21)$ \\
\hline \multicolumn{5}{|l|}{ Sex ${ }^{d}$} \\
\hline Male & $0.02(-1.62,1.68)$ & $-0.45(-2.40,1.47)$ & $0.76(0.34,1.67)$ & $1.44(0.48,5.05)$ \\
\hline Female & Ref & Ref & Ref & Ref \\
\hline \multicolumn{5}{|l|}{ Area } \\
\hline Urban (Area 25) & Ref & Ref & Ref & Ref \\
\hline Rural (Bonje) & $3.85(2.05,5.64)$ & $3.82(1.51,6.32)$ & $0.69(0.27,1.92)$ & $1.75(0.50,6.30)$ \\
\hline \multicolumn{5}{|l|}{ Education (years) } \\
\hline$\leq 5$ & $4.51(1.10,7.93)$ & $4.29(0.77,7.69)$ & $0.55(0.14,2.02)$ & $0.64(0.14,2.56)$ \\
\hline$>5 \leq 10$ & $1.29(-0.56,3.15)$ & $1.31(-0.57,3.18)$ & $0.78(0.30,2.03)$ & $0.86(0.31,2.39)$ \\
\hline$>10$ & Ref & Ref & Ref & Ref \\
\hline \multicolumn{5}{|l|}{ Occupation } \\
\hline Agricultural worker & $-1.06(-3.14,1.01)$ & $-1.11(-3.20,1.02)$ & $0.44(0.17,1.21)$ & $0.42(0.15,1.17)$ \\
\hline Non-agricultural worker & Ref & Ref & Ref & Ref \\
\hline \multicolumn{5}{|l|}{ Household monthly income (MK) ${ }^{\mathrm{e}}$} \\
\hline Unknown & $-1.86(-7.60,3.87)$ & $-2.26(-8.01,3.50)$ & $1.39(0.06,13.66)$ & $2.21(0.09,20.58)$ \\
\hline MK $0 \leq 20,000$ & Ref & Ref & Ref & Ref \\
\hline$M K>20,000$ & $-0.34(-2.16,1.47)$ & $-0.01(-1.85,1.87)$ & $1.32(0.54,3.23)$ & $1.05(0.40,2.78)$ \\
\hline \multicolumn{5}{|l|}{ BMI $\left(\mathrm{kg} / \mathrm{m}^{2}\right)$} \\
\hline $5 \mathrm{~kg} / \mathrm{m}^{2}$ increase & $-0.99(-2.8,0.09)$ & $-0.94(-2.02,0.17)$ & $2.00(1.293 .15)$ & $2.01(1.27,3.43)$ \\
\hline \multicolumn{5}{|l|}{ Fat Free Mass (kg) } \\
\hline (Per 5 kg increase) & $-0.02(-0.07,0.02)$ & $-0.02(-0.07,0.02)$ & $1.00(0.00,1.02)$ & $0.99(0.03,1.03)$ \\
\hline \multicolumn{5}{|l|}{ Healthy lifestyle choices } \\
\hline Non-smoker or alcohol drinker & $-1.49(-3.57,0.59)$ & $-1.43(-3.50,0.70)$ & $2.07(0.72,6.64)$ & $2.06(0.68,7.06)$ \\
\hline Smoker and alcohol drinker & Ref & Ref & Ref & Ref \\
\hline \multicolumn{5}{|l|}{ Regular meat-eater } \\
\hline Yes & $-0.40(-2.32,1.51)$ & $-0.33(-2.27,1.65)$ & $1.34(0.58,3.39)$ & $1.04(0.43,2.72)$ \\
\hline No & Ref & Ref & Ref & Ref \\
\hline
\end{tabular}

Hypertension $=$ systolic bp $\geq 140 \mathrm{mmHg}$, or diastolic bp $\geq 90 \mathrm{mmHg}$; Diabetes $=$ fasting glucose $>=7 \mathrm{mg} / ;$ Proteinuria $=\mathrm{ACR}>=30 \mathrm{mg} / \mathrm{mmol}$

aminimal adjustment for age, sex and area

ball variables mutually adjusted

cadjusted for sex and area

dadjusted for age and area

exchange rate (MK to USD) 0.001 at time of questionnaire

\section{Discussion}

We report the distribution of eGFR in participants without hypertension, diabetes, or heavy proteinuria, and estimate the prevalence and potential risk factors of reduced eGFR in an urban and rural study population.

The distribution of eGFR across the population sample showed a high proportion of participants with an eGFR $>120 \mathrm{ml} / \mathrm{min} / 1.73 \mathrm{~m}^{2}$, suggesting that low eGFR is not generally a health burden in this population. As we observed only two cases of eGFR $<60$ we conducted analyses using the cut-off eGFR $<90$. Observing so few cases of eGFR $<60$ in Malawi was unexpected, as the country has a similar climate (within a $2-4{ }^{\circ} \mathrm{C}$ range of endemic regions) and agricultural-led economy to other countries (in Central America and South Asia) where the rural population is at high risk (see Additional file 4, Table S4 for socioeconomic and environmental factor comparison). This 'negative' finding is important, as it contradicts current hypotheses that $\mathrm{CKDu}$ is endemic in tropical/subtropical countries and supports the contention that the causes of the epidemic(s) are unknown and more evidence is needed $[28,29]$. 
Table 3 Associations between sociodemographic and anthropometric characteristics and estimated glomerular filtration rate (eGFR) (fully adjusted) after removal of those with hypertension, diabetes and proteinuria, Area $25(n=243)$ and Bonje $(n=578)$

\begin{tabular}{|c|c|c|c|}
\hline \multirow[t]{4}{*}{ Variable } & Bonje & Bonje & Area 25 \\
\hline & Model 1 & Model 2 & Model 3 \\
\hline & eGFR & eGFR $<90$ & eGFR \\
\hline & Coefficient $(95 \% \mathrm{Cl})$; & Coefficient $(95 \% \mathrm{Cl})^{\mathrm{a}}$; & Coefficient $(95 \% \mathrm{Cl})^{\mathrm{a}}$; \\
\hline \multicolumn{4}{|l|}{ Age } \\
\hline Per 10-year increase & $-9.00(-9.79,-8.22)$ & $3.09(2.12,4.59)$ & $-8.14(-10.61,-6.23)$ \\
\hline \multicolumn{4}{|l|}{ Sex } \\
\hline Male & $-0.10(-2.45,2.23)$ & $1.55(0.37,8.28)$ & $-1.62(-5.29,2.05)$ \\
\hline Female & Ref & Ref & Ref \\
\hline \multicolumn{4}{|l|}{ Education (years) } \\
\hline$\leq 5$ & $4.19(0.39,7.99)$ & $0.92(0.17,4.58)$ & $5.59(-2.63,13.82)$ \\
\hline$>5 \leq 10$ & $1.65(-0.38,3.69)$ & $1.04(0.33,3.40)$ & $-0.62(-5.49,4.24)$ \\
\hline$>10$ & Ref & Ref & Ref \\
\hline \multicolumn{4}{|l|}{ Occupation } \\
\hline Agricultural worker & $-1.04(-3.14,1.04)$ & $0.45(0.17,1.27)$ & $0.99(-13.76,15.75)$ \\
\hline Non-agricultural worker & Ref & Ref & Ref \\
\hline \multicolumn{4}{|l|}{ Household monthly income $(\mathrm{MK})^{\mathrm{b}}$} \\
\hline Unknown & $-4.46(-11.76,2.82)$ & $3.18(0.11,37.04)$ & $-0.83(-11.10,9.43)$ \\
\hline MK $0 \leq 20,000$ & Ref & Ref & Ref \\
\hline MK $>20,000$ & $0.35(-1.67,2.37)$ & $1.02(0.37,2.73)$ & $-1.73(-6.45,2.98)$ \\
\hline \multicolumn{4}{|l|}{$\mathrm{BMI}\left(\mathrm{kg} / \mathrm{m}^{2}\right)$} \\
\hline $5 \mathrm{~kg} / \mathrm{m}^{2}$ increase & $-0.62(-1.97,0.73)$ & $1.89(1.06,3.81)$ & $-1.58(-3.54,0.36)$ \\
\hline \multicolumn{4}{|l|}{ Fat Free Mass (kg) } \\
\hline (Per 5 kg increase) & $-0.01(-0.07,0.04)$ & $0.92(0.58,1.01)$ & $-0.02(-0.11,0.06)$ \\
\hline \multicolumn{4}{|l|}{ Healthy lifestyle choices } \\
\hline Non-smoker or alcohol drinker & $-1.40(-3.95,1.13)$ & $1.52(0.43,5.87)$ & $-1.84(-5.83,2.14)$ \\
\hline Smoker and alcohol drinker & Ref & Ref & Ref \\
\hline \multicolumn{4}{|l|}{ Regular meat-eater } \\
\hline Yes & $-0.10(-1.77,2.77)$ & $1.05(0.41,2.93)$ & $-1.95(-7.38,3.46)$ \\
\hline No & Ref & Ref & Ref \\
\hline
\end{tabular}

Hypertension = systolic $\mathrm{bp} \geq 140 \mathrm{mmHg}$, or diastolic $\mathrm{bp} \geq 90 \mathrm{mmHg}$; Diabetes $=$ fasting glucose $>=7 \mathrm{mg} / \mathrm{l} ;$ Proteinuria $=\mathrm{ACR}>=30 \mathrm{mg} / \mathrm{mmol}$ ${ }^{a}$ All variables mutually adjusted

bxchange rate (MK to USD) 0.001 at time of questionnaire

In our study population, lower eGFR and risk of eGFR $<90$ was associated with increasing age, and increasing BMI was associated with increased risk of eGFR $<90$. These factors are commonly associated with reduced kidney function both with and without diabetes $[30,31]$, suggesting that the small poportion of partcipants with reduced eGFR is likely due to age-related renal decline.

Contrary to the current literature that CKDu is likely an agricultural disease [2, 32-34], we observed a positive association between rural area and eGFR after adjustment despite the higher crude prevalence observed in this area. Furthermore, we did not observe a high prevalence of reduced eGFR in the working age rural population. In Bonje, rice is the predominant crop, and we assume most agricultural workers in this population work in the neighbouring schemes. However, we observed no increased risk in this occupational group, even though the increased risks observed in Central America and South Asia are for agricultural workers, specifically rice workers $[8,35-37]$. This finding poses the question why we are observing inter-regional differences in risk of reduced eGFR in similar occupational groups working in similar climatic conditions, and therefore could count against the current heat hypothesis [28].

Prior to this study and other CKD research in Malawi [18], CKD was not identified as a health burden in this region, however eGFR was not measured using the 
DEGREE protocol diagnostic definitions. In the Malawian population, it is likely that survival with reduced renal function in this region is poor, which may result in a lower prevalence than would be found in settings with more developed health services. This factor could provide the primary explanation for the low prevalence of CKD and (potential) CKDu observed across the DEGREE sample population.

Our study has some limitations. Firstly, due to the crosssectional nature of this study, we had one eGFR measure, and therefore could not differentiate acute kidney injury (AKI) from CKD. Therefore - as is commonly experienced in epidemiological studies - we may have misclassified some AKI as reduced eGFR and overestimated reduced eGFR (< 90) prevalence. There is debate surrounding the diagnostic criteria for CKDu which largely surrounds the exclusion of hypertension and proteinuria, both of which are both causes and consequences of advanced CKD (and CKDu). At early stages of the disease, proteinuria is uncommon in $\mathrm{CKDu}$, and hypertension is not present, by definition; however, both are common in other forms of CKD (including diabetic glomerular disease), and at the population level, most disease is likely to be detected at earlier stages. Currently, the exclusion criteria for hypertension when defining $\mathrm{CKDu}$ varies by geographical location, and there is not yet an internationally accepted definition of CKDu [1]. For example, in Meso America those with hypertension with target organ damage or a blood pressure of $\geq 160 \mathrm{mmHg} / 100$ $\mathrm{mmHg}$ are excluded from further analyses, whereas in Sri Lanka those receiving hypertension treatment or those with a blood pressure of $\geq 160 \mathrm{mmHg} / 100 \mathrm{mmHg}$ over two measurements are excluded [1]. Under the DEGREE protocol, a more conservative hypertension cut-off of $\geq 140 \mathrm{mmHg} / \geq$ $90 \mathrm{mmHg}$ is used. This cut-off has also been applied to international studies conducted in India, Sri Lanka and Meso America, and results have still shown there is a substantial burden of CKDu in population samples [2-4]. The rationale for the 'DEGREE definition' of eGFR $<60$ as a proxy for $\mathrm{CKDu}$ is therefore that although this may result in misclassification of a few cases of advanced CKDu as non-CKDu, this is likely to be rare, whereas not doing such exclusions would lead to a large overestimation of CKDu prevalence. Secondly, sampling this nested population could have resulted in selection bias, potentially attenuating estimates. Rural participants were easily located and had a $70 \%$ response rate. However, Lilongwe had a $45 \%$ response rate, due to external employment, which is likely to be casual agricultural labour. As a result of differential response rates between the urban and rural sites, statistical power was limited which therefore did not allow us to classify this study as having a negative result, but possibly a "non-positive" result, which can be seen in the wide confidence intervals for age in both linear and logistic regression models (Tables 2, 3).
Perhaps most crucially, the CKD-EPI equation has not yet been validated for the African population, which is a major limiting factor in these analyses.

The main strengths of the study are the use of a random selection of population-based participants. Furthermore, DEGREE CKDu definitions were used [1], which aim to facilitate international comparisons of CKDu prevalence and help describe risk factors and identify the causes and mechanisms leading to $\mathrm{CKDu}$.

\section{Conclusion}

In conclusion, our findings indicate that in Malawi reduced eGFR consistent with the definition of CKDu is non-existent. eGFR $<90$ in the absence of known CKD risk factors was present, but these cases were associated with traditional CKD factors, age, and BMI. Contrary to the current literature that CKDu is a rural disease disproportionately affecting males, we observed a low prevalence of lower eGFR amongst rural males, and no rural-urban or sex-specific associations with lower eGFR or risk of eGFR $<90$ were found. These findings suggest that due to the absence of site, occupation, and sex associations, $\mathrm{CKD}(\mathrm{u})$ is not present at least to the extent that it has been observed in other tropical or sub-tropical countries in Central America and South Asia.

This research is informative to the CKDu research field, as we did not observe the disease in a region which has a similar agricultural-led economy and climate to $\mathrm{CKDu}$ endemic regions. These analyses are also important in informing the geographical distribution of CKDu suggesting that the disease is localized to specific countries, as opposed to the entire tropical or subtropical region.

\section{Supplementary information}

Supplementary information accompanies this paper at https://doi.org/10. 1186/s12882-020-02034-X.

Additional file 1 : Table S1. Sociodemographic and anthropometric characteristics of overall study participants (prior to exclusion of population with diabetes, hypertension, and heavy proteinuria).

Additional file $\mathbf{2}$ : Table S2. Linear and logistic regression models, showing both minimally and fully adjusted models Bonje $(n=578)$.

Additional file $\mathbf{3}$ : Table S3. Linear regression models, showing both minimally and fully adjusted models, Area $25(n=243)$.

Additional file 4 : Table S4. A comparison of socioeconomic and environmental factors between non-endemic Malawi and endemic regions of Central America and South Asia.

\section{Abbreviations}

ACR: Albumin: creatinine ratio; AKl: Acute kidney injury; BIA: Bio impedance analysis; BMI: Body mass index; Cl: Confidence interval; CKD-EPI equation: The CKD Epidemiology Collaboration equation; CKDu: Chronic kidney disease of unknown cause; DEGREE: The Disadvantaged Populations eGFR

Epidemiology study; eGFR: Estimated glomerular filtration rate; FFM: Fat-free mass; HDSS: Health and Demographic Surveillance Site; IDMS: Isotope dilution mass spectrometry; IQR: Interquartile range; LMIC: Low-and-middleincome country; MK: Malawian Kwacha; OR: Odds ratio; SD: Standard deviation; USD: US Dollar 


\section{Acknowledgements}

Not applicable

\section{Authors' contributions}

N.P., B.C., and M.N. designed the study; J.P., W.N., and A.C. planned logistics and collected bio samples; S.A.H., analysed data, drafted paper and made the figures; N.P., B.C., M.N., J.P., W.N., A.C., D.F., and P.V. revised the paper, all authors read and approved the final manuscript.

\section{Funding}

The results reported herein correspond to specific aims of grant MRC GCRF Foundation Grant MR/P02386X/1 which funded the cross-sectional study data collection and laboratory analyses in the United Kingdom. This work was also supported by grants from the Medical Research Council - Public Health England PhD studentship funding, and the Imperial College Medical Research Council Supplement Scheme \#63.

Statistical data analyses and manuscript writing was conducted by the authors, of which the specific roles are described below.

\section{Availability of data and materials}

The datasets analysed during the current study are not publicly available due to the sensitive nature of biological measurements and unique identifiers in the dataset.

\section{Ethics approval and consent to participate}

Ethical approval was granted by the Malawi National Health Sciences Research Committee protocol number \#1912 (Lilongwe, Malawi), and the London School of Hygiene and Tropical Medicine Ethics Committee protocol \#14709 (London, UK). Signed informed consent forms were obtained from all participants.

\section{Consent for publication}

Not applicable

\section{Competing interests}

None declared

\section{Author details}

'Department of Epidemiology and Biostatistics, Imperial College London, London, UK. ${ }^{2}$ MRC Centre for Environment and Health, Imperial College London, London, UK. ${ }^{3}$ Imperial College London, School of Public Health, London, UK. ${ }^{4}$ Malawi Epidemiology and Intervention Research Unit, Lilongwe, Malawi. ${ }^{5}$ Institute of Cardiovascular Science, University College London, London, UK. ${ }^{6}$ Departments of Infectious Disease Epidemiology, London School of Hygiene and Tropical Medicine, London, UK. ${ }^{7}$ Centre for Nephrology, Division of Medicine, University College London, London, UK. ${ }^{8}$ Department of Medical Statistics, London School of Hygiene and Tropical Medicine, London, UK. ${ }^{9}$ Centre for Global NCDs, London School of Hygiene and Tropical Medicine, London, UK.

Received: 12 December 2019 Accepted: 20 August 2020

Published online: 07 September 2020

\section{References}

1. Caplin B, Jakobsson K, Glaser J, Nitsch D, Jha V, Singh A, et al. International collaboration for the epidemiology of eGFR in low and middle income populations - rationale and core protocol for the disadvantaged populations eGFR epidemiology study (DEGREE). BMC Nephrol. 2017:18(1):1.

2. Caplin B, Yang CW, Anand S, Levin A, Madero M, Saran R, et al. The International Society of Nephrology's International Consortium of Collaborators on Chronic Kidney Disease of Unknown Etiology: report of the working group on approaches to population-level detection strategies and recommendations for a minimum dataset. Kidney Int. 2019;95(1):4-10.

3. Ramírez-Rubio O, Amador JJ, Kaufman JS, Weiner DE, Parikh CR, Khan U, et al. Urine biomarkers of kidney injury among adolescents in Nicaragua, a region affected by an epidemic of chronic kidney disease of unknown aetiology. Nephrol Dial Transplant. 2016;31(3):424-32

4. Wijkstrom J, Gonzalez-Quiroz M, Hernandez M, Trujillo Z, Hultenby K, Ring A, et al. Renal morphology, clinical findings, and progression rate in Mesoamerican nephropathy. Am J Kidney Dis. 2017;69:626.
5. Lebov JF, Valladares E, Pena R, Pena EM, Sanoff SL, Cisneros EC, et al. A population-based study of prevalence and risk factors of chronic kidney disease in Leon, Nicaragua. Can J Kidney Health Dis. 2015;2(1):6.

6. Torres C, Aragon A, Gonzalez M, Lopez I, Jakobsson K, Elinder CG, et al. Decreased kidney function of unknown cause in Nicaragua: a communitybased survey. Am J Kidney Dis. 2010;55(3):485-96.

7. O'Callaghan-Gordo C, Shivashankar R, Anand S, Ghosh S, Glaser J, Gupta R, et al. Prevalence of and risk factors for chronic kidney disease of unknown aetiology in India: secondary data analysis of three population-based crosssectional studies. BMJ Open. 2019;9(3):e023353.

8. Jayasekara KB, Dissanayake DM, Sivakanesan R, Ranasinghe A, Karunarathna $\mathrm{RH}$, Priyantha Kumara GW. Epidemiology of chronic kidney disease, with special emphasis on chronic kidney disease of uncertain etiology, in the north central region of Sri Lanka. J Epidemiol. 2015;25(4):275-80.

9. Levine KE, Redmon JH, Elledge MF, Wanigasuriya KP, Smith K, Munoz B, et al. Quest to identify geochemical risk factors associated with chronic kidney disease of unknown etiology (CKDu) in an endemic region of $\mathrm{Sr}$ Lanka-a multimedia laboratory analysis of biological, food, and environmental samples. Environ Monit Assess. 2016:188(10):548.

10. Wasana HMS, Aluthpatabendi D, Bandara J. Drinking water quality assessment towards "chronic kidney disease of unknown etiology (CKDu)" in north central province (NCP) of Sri Lanka; 2012.

11. Lopez-Marin L, Chavez Y, Garcia XA, Flores WM, Garcia YM, Herrera R, et al. Histopathology of chronic kidney disease of unknown etiology in Salvadoran agricultural communities. MEDICC Rev. 2014;16(2):49-54.

12. International Working Group on CKDu W. Designing a step-wise approach to estimate the burden and to understand the etiology of CKDu in Sri Lanka. Geneva: World Health Organization; 2016.

13. Roncal-Jimenez C, García-Trabanino R, Barregard L, Lanaspa M, Wesseling C, Harra T, et al. Heat stress nephropathy from exercise-induced uric acid crystalluria: a perspective on Mesoamerican nephropathy. 2015.

14. Wesseling C, Aragón A, González M, Weiss I, Glaser J, Bobadilla N, et al. Kidney function in sugarcane cutters in Nicaragua - a longitudinal study of workers at risk of Mesoamerican nephropathy. Environ Res. 2016;147:125-32.

15. Glaser J, Lemery J, Rajagopalan B, Diaz HF, Garcia-Trabanino R, Taduri G, et al. Climate change and the emergent epidemic of CKD from heat stress in rural communities: the case for heat stress nephropathy. Clin J Am Soc Nephrol. 2016;10.

16. Valcke M, Levasseur ME, Soares da Silva A, Wesseling C. Pesticide exposures and chronic kidney disease of unknown etiology: an epidemiologic review. Environ Health. 2017;16(1):49.

17. Wanigasuriya K, Peiris-John R, Wickremasinghe R. Chronic kidney disease of unknown aetiology in Sri Lanka: is cadmium a likely cause? 2011.

18. Nakanga W, Prynn J, Banda L, Kalyesubula R, Tomlinson L, Nyirenda M, et al. Prevalence of impaired renal function among rural and urban populations: findings of a cross-sectional study in Malawi [version 1; peer review: awaiting peer review]. Wellcome Open Res. 2019;4:92.

19. A.C C, Dube A, Mboma S, Price A, Chihana M, Jahn A, et al. Profile: The Karonga Health and Demographic Surveillance System. Int J Epidemiol. 2012;41:676-85.

20. Crampin ACKN, Amberbir A, Musicha C, Koole O, Tafatatha T, Branson K, Saul J, Mwaiyeghele E, Nkhwazi L, Phiri A, Price AJ, Mwagomba B, Mwansambo C, Jaffar S, Moffat Joha Nyirenda MJ. Hypertension and diabetes in Africa: design and implementation of a large population-based study of burden and risk factors in rural and urban Malawi. Emerg Themes Epidemiol. 2016;13:3

21. Matsha TE, Kengne AP, Masconi KL, Yako YY, Erasmus RT. APOL1 genetic variants, chronic kidney diseases and hypertension in mixed ancestry south Africans. BMC Genet. 2015;16:69.

22. Peters PJ, Moore DM, Mermin J, Brooks JT, Downing R, Were W, et al. Antiretroviral therapy improves renal function among HIV-infected Ugandans. Kidney Int. 2008;74(7):925-9.

23. Aryee C, Owiredu WK, Osei-Yeboah J, Owusu-Dabo E, Laing EF, Owusu IK. An analysis of anthropometric indicators and modifiable lifestyle parameters associated with hypertensive nephropathy. Int J Hypertens. 2016;2016: 6598921.

24. Ranque B, Menet A, Boutouyrie P, Diop IB, Kingue S, Diarra M, et al. Arterial stiffness impairment in sickle cell disease associated with chronic vascular complications: the multinational African CADRE study. Circulation. 2016; 134(13):923-33. 
25. Eastwood JB, Kerry SM, Plange-Rhule J, Micah FB, Antwi S, Boa FG, et al. Assessment of GFR by four methods in adults in Ashanti, Ghana: the need for an eGFR equation for lean African populations. Nephrol Dial Transplant. 2010;25(7):2178-87.

26. The Renal Association. CKD Stages: Renal Association. 2019. Available from: https://renal.org/information-resources/the-uk-eckd-guide/ckd-stages/

27. Greenland S, Daniel R, Pearce N. Outcome modelling strategies in epidemiology: traditional methods and basic alternatives. Int J Epidemiol. 2016:45(2):565-75.

28. Pearce N, Caplin B. Let's take the heat out of the CKDu debate: more evidence is needed. Occup Environ Med. 2019;76(6):357-9.

29. Pearce N, Caplin B, Gunawardena N, Kaur P, O'Callaghan-Gordo C, Ruwanpathirana T. CKD of unknown cause: a global epidemic? Kidney Int Rep. 2019;4(3):367-9.

30. O'Hare AM, Choi Al, Bertenthal D, Bacchetti P, Garg AX, Kaufman JS, et al. Age affects outcomes in chronic kidney disease. J Am Soc Nephrol. 2007; 18(10):2758-65.

31. Herrington WG, Smith M, Bankhead C, Matsushita K, Stevens S, Holt T, et al. Body-mass index and risk of advanced chronic kidney disease: Prospective analyses from a primary care cohort of 1.4 million adults in England. PLoS One. 2017;12(3):e0173515-e.

32. Wesseling C, van Wendel de Joode B, Crowe J, Rittner R, Sanati NA Hogstedt C, et al. Mesoamerican nephropathy: geographical distribution and time trends of chronic kidney disease mortality between 1970 and 2012 in Costa Rica. Occup Environ Med. 2015;72(10):714-21.

33. Valdés RH, Orantes CM, López MA, Marín LL, Arévalo PA, Smith González MJ, et al. Clinical characteristics of chronic kidney disease of non-traditional causes in women of agricultural communities in El Salvador. Clin Nephrol. 2015;83:56-63.

34. Bailey PK, Tomson CR, Kinra S, Ebrahim S, Radhakrishna KV. Differences in estimation of creatinine generation between renal function estimating equations in an Indian population: cross-sectional data from the Hyderabad arm of the Indian migration study. BMC Nephrol. 2013;14:30.

35. Weaver VM, Fadrowski JJ, Jaar BG. Global dimensions of chronic kidney disease of unknown etiology (CKDu): A modern era environmental and/or occupational nephropathy? BMC Nephrol. 2015;16(1):145

36. Orantes-Navarro CM, Herrera-Valdes R, Almaguer-Lopez M, Lopez-Marin L, Vela-Parada XF, Hernandez-Cuchillas M, et al. Toward a comprehensive hypothesis of chronic interstitial nephritis in agricultural communities. Adv Chronic Kidney Dis. 2017;24(2):101-6.

37. Garcia-Trabanino R, Jarquin E, Wesseling C, Johnson RJ, Gonzalez-Quiroz M, Weiss I, et al. Heat stress, dehydration, and kidney function in sugarcane cutters in El Salvador - a cross-shift study of workers at risk of Mesoamerican nephropathy. Environ Res. 2015;142:746-55.

\section{Publisher's Note}

Springer Nature remains neutral with regard to jurisdictional claims in published maps and institutional affiliations.

Ready to submit your research? Choose BMC and benefit from:

- fast, convenient online submission

- thorough peer review by experienced researchers in your field

- rapid publication on acceptance

- support for research data, including large and complex data types

- gold Open Access which fosters wider collaboration and increased citations

- maximum visibility for your research: over $100 \mathrm{M}$ website views per year

At $\mathrm{BMC}$, research is always in progress.

Learn more biomedcentral.com/submissions 